\title{
Cold tolerance in cypress (Cupressus sempervirens L.): a physiological and molecular study
}

\author{
Paolo Baldi • Luca Pedron • Ari M. Hietala • \\ Nicola La Porta
}

Received: 15 August 2009/Revised: 20 May 2010 / Accepted: 8 June 2010/Published online: 6 July 2010

(C) The Author(s) 2010. This article is published with open access at Springerlink.com

\begin{abstract}
Twenty cypress accessions were tested for freezing tolerance. After freezing to $-15^{\circ} \mathrm{C}$, differences among cypress accessions were tested by measuring electrolyte leakage and chlorophyll fluorescence. Based on these data, cypress accessions showing contrasting freezing tolerance were subjected to transcript profiling of candidate genes upon the development of cold hardening, with the ultimate goal of providing a scientific basis for selecting/breeding cypress genotypes with higher tolerance to low temperature. Nine different cypress genes were selected: a heat shock protein, a putative chaperonin, a chlorophyll-binding protein, a serine/threonine protein kinase, a putative exonuclease, a dehydrin, and three senescenceassociated proteins. Transcript levels of these genes were profiled during cold hardening under controlled conditions using real-time reverse-transcription-polymerase chain reaction. While the genes showed regulation patterns common to both cypress accessions, in the case of chaperonin, exonuclease, and some senescence-associated proteins, clonal differences in gene regulation were found. The potential relationship of these differences with cold tolerance is discussed.
\end{abstract}

Keywords Abiotic stress - Low temperature

Chlorophyll fluorescence Electrolyte leakage .

Gene expression $\cdot$ RT-PCR

Communicated by S. Aitken

P. Baldi $(\bowtie) \cdot$ L. Pedron $\cdot$ N. La Porta

IASMA Research and Innovation Center,

Fondazione Edmund Mach Via E. Mach 1,

38010, San Michele all'Adige,

$\mathrm{TN}$, Italy

e-mail: paolo.baldi@iasma.it

A. M. Hietala

The Norwegian Forest and Landscape Institute,

Høgskoleveien 8, Pb. 115, 1432 Ås, Norway

\section{Introduction}

Common cypress (Cupressus sempervirens L.) is a conifer species native to the eastern Mediterranean region. The tree is mainly used as an ornamental tree due to its conical crown shape, but it can also be used for timber, as a privacy screen, and protection against wind as well. Moreover, cypress has proved to be very suitable as a pioneer species for reforestation as it can tolerate poor, barren, and superficial soils. For all these reasons, cypress has been introduced in geographic areas that extend far beyond its natural distribution (Bagnoli et al. 2009), and today the tree is widely cultivated throughout the southwestern Europe. Cypress is relatively adaptable to a range of temperatures. Although it prefers dry hot summers and mild winters, it can also tolerate more continental climates. Mature cypress can usually survive harsh winters with temperatures below $-15^{\circ} \mathrm{C}$ (Larcher 2001), and there are records of resistance at $-23^{\circ} \mathrm{C}$ (Raddi and Panconesi 1989), but under such conditions, severe damage with loss of considerable crown area may occur.

A global climate change with a general temperature increase has been predicted (IPCC 2007). This change has been particularly evident in the last 30 years, when average surface temperatures increased by $0.2^{\circ} \mathrm{C}$ per decade (Hansen et al. 2006). As a result, natural distributions of animals and plants have already shifted northwards and towards higher elevations within the boreal hemisphere (Lenoir et al. 2008; Kelly and Goulden 2008). It is therefore likely that the distribution of cypress will gradually follow the same trend as the tree is planted more northward in Europe (Zocca et al. 2008). At the species' range margins, the possibility of damage due to an exceptionally cold winter will increase, making low-temperature tolerance one of the main characters to be considered in the breeding of cypress for the northern territories. 
Low-temperature resistance in plants is a very complex trait, involving many different metabolic pathways and cell compartments (Hannah et al. 2005). The main effect of cold damage in plants is the disruption of cellular membranes and structures due to the formation of extracellular ice crystals which induce a rapid loss of water and consequent desiccation (Pearce 2001; Larcher 2003). Several methods have been developed to quantify the frost damage to plant membranes. The most frequently used is the determination of electrolyte leakage from plant tissue after freezing and thawing using conductivity measurements (Rohde et al. 2004). This method provides information about the ability of plant membranes to function as a semi-permeable barrier for intracellular ions, but does not take into account the damage to chloroplast membranes. As shown by electron microscopy (Hincha and Schmitt 1992), chloroplasts are also damaged during freezing and thawing, resulting in inactivation of photosynthesis (Krause et al. 1988). Chlorophyll fluorescence measurements, through the calculation of the maximum quantum efficiency of photosystem II $\left(\mathrm{F}_{\mathrm{V}} / \mathrm{F}_{\mathrm{M}}\right.$; Mohammed et al. 1995), can be effectively used to monitor the loss of photosynthesis efficiency, as originally demonstrated in spinach (Schmidt et al. 1986). Regarding conifers, this method has been used to detect freezing damage in needles (Lindgren and Hällgren 1993; Binder and Fielder 1996; Baker and Rosenqvist 2004, to examine photosynthesis efficiency in canker-susceptible and resistant cypress clones (Muthuchelian et al. 2005), and to measure aging-associated changes in cypress (La Porta et al. 2006).

From a molecular point of view, a great number of genes are regulated by plant exposure to low temperatures (Smallwood and Bowles 2002). The majority of plants living in temperate climates are capable of developing a certain degree of frost resistance when exposed for some days to low, but nonfreezing temperatures (Chinusamy et al. 2007). This phenomenon is called cold acclimation or hardening and involves changes in cell metabolism and gene expression (Thomashow 1999). It has been shown in many plant species that a considerable transcriptional reprogramming takes place during hardening. A typical example is represented by dehydrins, which are thought to play a cryoprotective role and are commonly induced by different abiotic stresses such as drought and salt treatment. When members of the dehydrin gene family were surveyed in haplotypes of Scots pine sampled in European populations showing divergence for cold tolerance, both nucleotide polymorphisms and significant differentiation in allele frequency or haplotype structure were detected between populations (Wachowiak et al. 2009). The interaction between cold and other stress responses has been demonstrated by the low temperature induction of heat shock protein (HSP) family, which is typically up-regulated by elevated temperatures (Ukaji et al. 1999; Lopez-Matas et al. 2004). Another trait which has been found to interact with cold acclimation is leaf senescence (Masclaux-Daubresse et al. 2007). During low-temperature exposure plants accumulate sugars (Cook et al. 2004), an event that has been found to coincide with the onset of senescence in Arabidopsis and tobacco (Masclaux et al. 2000; Diaz et al. 2005). Cold acclimation in many woody plants is initially induced by short photoperiod and low, non-freezing temperatures. Using a proteomics approach for investigating cold acclimation in peach, Renaut et al. (2008) showed that low temperature was the most significant factor affecting the proteome, while the combination of low temperature and short photoperiod had either a synergistic or additive impact on the expression of some proteins. In addition, a number of genes with known and unknown functions have been found to be regulated by low temperature in many different species, this underlying the extreme complexity of plant cold response (Chinusamy et al. 2007.

Very few data are presently available regarding cypress cold response and adaptation. In a former work (Pedron et al. 2009), a first attempt was made to give an insight into the molecular mechanisms regulated by low temperature in this still poorly studied woody perennial species. Nevertheless, many questions are still to be answered and many aspects of cypress cold acclimation remain untouched. First of all, it is unknown if there are differences in cold resistance among different cypress accessions and if such differences can be effectively measured. In the present study, physiological and molecular tools have been combined in order to highlight differences in low-temperature response among different cypress genotypes. The possibility to correlate such differences to cold resistance is discussed.

\section{Materials and methods}

Plant material and growing conditions

Twenty 10-year-old cypress genotypes (identified as accessions no. 7, 15, 23, 26, 27, 30, 32, 33, 41, 42, 43, 46, 48, $52,64,67,70,75,88$, and 95) were grown in a nursery located in Riva del Garda, Italy. These non-related genotypes, obtained by vegetative propagation from natural trees growing in different locations in Tuscany, were derived from a 30-year-long breeding program of the IPPCNR of Florence against cypress canker (La Porta et al. 2005). Two ramets of each genotype were grown in pots with a sand/soil mix $(50 \% / 50 \%)$, and prior to cold treatment the plants were acclimated at $22^{\circ} \mathrm{C}$ in a growing chamber for 21 days (14 h light $160 \mu$ mol photons $\mathrm{m}^{-2} \mathrm{~s}^{-1}$ and $10 \mathrm{~h}$ dark). The plants were cold-treated in a daily regime of $14 \mathrm{~h}$ light $\left(160 \mu \mathrm{mol}\right.$ photons $\left.\mathrm{m}^{-2} \mathrm{~s}^{-1}\right)$ and $10 \mathrm{~h}$ 
dark at $3{ }^{\circ} \mathrm{C}$ for 15 days. Leaf samples were collected from each plant before cold treatment (control) and after 1, 3, 7 and 15 days of incubation at $3^{\circ} \mathrm{C}$. All samples were immediately frozen in liquid nitrogen and stored at $-75^{\circ} \mathrm{C}$ until processing for mRNA isolation.

\section{Freezing cycles}

Freezing cycles were performed essentially as described by Cavender-Bares (2007). In brief, branches with leaves from current-year shoots of similar length and diameter were cut from the three uppermost whorls of each seedling and washed under running water, placed in dark and frozen water-filled tubes in a temperature-controlled freezer box overnight at minimum temperatures of $-15^{\circ} \mathrm{C}$. The temperature, considered the lower limit for the species in study, was chosen to mimic the worst winter conditions that cypress can survive in northern regions. The freezing and thawing rate was $0.25^{\circ} \mathrm{Cmin}^{-1}$.

To allow recovery, frozen samples were placed in a dark chamber for $24 \mathrm{~h}$ at room temperature before measurement of the ratio of variable fluorescence over the maximum fluorescence value (Fv/Fm) (Boorse et al. 1998).

\section{Chlorophyll fluorescence}

Three branches per plant, excised from different parts of the crown of one ramet of each genotype, were collected on November 28th 2006 and tested in laboratory conditions. All measurements of chlorophyll fluorescence were performed with a portable PAM-2000 Chlorophyll Fluorometer (Walz, Effeltrich, Germany) just after the treatment. Before each measurement, the sample was dark-adapted for $30 \mathrm{~min}$. The angle and distance from the leaf surface to the end of the optic fiber cable were kept constant during the experiments. The leaves were exposed to a 0.8 -s saturated flash of approximately $6000 \mu \mathrm{mol} \mathrm{m} \mathrm{m}^{-2}$ to obtain the maximal fluorescence yield $(\mathrm{Fm})$. All measurements of minimum fluorescence yield (Fo) were performed with the measuring beam set to a frequency of $600 \mathrm{~Hz}$, whereas all measurements of Fm were performed with saturating flash automatically switching to $20 \mathrm{kHz}$. The $\mathrm{F}_{\mathrm{V}} / \mathrm{F}_{\mathrm{M}}$ ratio was calculated automatically according to measured minimum and maximum fluorescence yield. The $\mathrm{F}_{\mathrm{V}} / \mathrm{F}_{\mathrm{M}}$ ratio $\left[\mathrm{F}_{\mathrm{V}} / \mathrm{F}_{\mathrm{M}}=\right.$ $(\mathrm{Fm}-\mathrm{Fo}) / \mathrm{Fm}]$ was used as a measure of the potential quantum yield, the maximum photochemical efficiency of photosystem II (La Porta et al. 2004).

\section{Electrolyte leakage}

Branches were collected from one ramet of each genotype on November 25th 2006 and tested in laboratory conditions. Samples were first rinsed in distilled water and then wiped and dried at room temperature. Twenty grams of leaves for each clone was excised from the shoots. After the freezing treatments, the samples were progressively thawed to $4^{\circ} \mathrm{C}$ for $2 \mathrm{~h}$, cut in pieces of $0.8 \mathrm{~cm}$, and incubated for $24 \mathrm{~h}$ in a shaker at $23^{\circ} \mathrm{C}$ under bank of lights in plastic vials containing $10 \mathrm{ml}$ of distilled, deionized water. Electric conductivity was measured using a WTW $340 \mathrm{i}$ conductivity meter (Wissenschaftlich-Technische Werkstätten $\mathrm{GmbH}$, Weilheim, Germany). After these first measurements, the vials with the solution were twice frozen at $-80^{\circ} \mathrm{C}$ for $12 \mathrm{~h}$ in order to completely destroy the integrity of the membranes. Then the solutions where again thawed and shaken for another $24 \mathrm{~h}$ under bank of lights, and the final conductivity measurements were made with the same procedure as described above. Ionic leakage was calculated as percentage between initial and final measurements.

\section{Transcript level analysis}

Verification of transcript levels of selected genes was performed by real-time reverse-transcription-polymerase chain reaction (RT-PCR). Total RNA was extracted from $3 \mathrm{~g}$ of cypress leaves using a modified hot borate method, as described in Moser et al (2004). Contaminating DNA was removed by using a DNA-Free kit (Ambion, Austin, TX, USA.) with $2 \mathrm{U}$ of DNase I per sample and incubated at $37^{\circ} \mathrm{C}$ for $30 \mathrm{~min}$. Total RNA was quantified with a VersaFluor fluorometer (Bio-Rad, Hercules, CA, USA.) and a RiboGreen RNA quantification kit (Molecular Probes, Eugene, OR, USA) according to the manufacturer's instructions. Total RNA was normalized between samples: $400 \mathrm{ng}$ of total RNA was reverse transcribed with TaqMan reverse transcription reagents (Applied Biosystems, Foster City, CA, USA.) according to the manufacturer's instructions with $2.5 \mathrm{U}$ of reverse transcriptase per sample and $2.5 \mu \mathrm{M}$ oligo (dT) primers in a $50-\mu \mathrm{l}$ reaction volume. The resulting cDNA was threefold diluted prior to real-time PCR quantification. The genes, subjected to transcript profiling, were selected from a set of 156 sequences previously isolated in our laboratory and were chosen according to their putative functions so that the set represents several molecular pathways. Primers (Table 1) were designed with the Primer Express software 1.5a (Applied Biosystems, Foster City, CA, USA). Primers developed for cyplp001 were not specific, as multiple melt peaks for PCR products were detected representing several members of the gene family due to their sequence similarity and co-regulation. Real-time PCR quantification was performed as described in Pedron et al. (2009). Briefly, $3 \mu \mathrm{l}$ of template was amplified in a $25-\mu$ reaction volume with a primer concentration of $50 \mathrm{nM}$. PCR reaction was performed as follows: $95^{\circ} \mathrm{C}$ for $2 \mathrm{~min}$ of initial denaturation, followed by 45 cycles at $95^{\circ} \mathrm{C}$ for $15 \mathrm{~s}, 60^{\circ} \mathrm{C}$ for 
Table 1 Primer sequences used for profiling transcript levels of candidate genes by real-time RT-PCR

\begin{tabular}{ll}
\hline Primer name & Primer sequence \\
\hline Cyplp001For & 5'-GACATGCCCGGCGTTAAA-3' \\
Cyplp001Rev & 5'-CCGCTGATTGTCAGCACATTT-3' \\
Cyplp004For & 5'-TGCAACTGAGATCATCTCTTCACTT-3' \\
Cyplp004Rev & 5'-CCTGTTGTAAATCAATCCCAACTTT-3' \\
Cyplp005For & 5'-GGGAGATTAGCCATGTCCTCTATG-3' \\
Cyplp005Rev & 5'-AGTTCTCAATTGGCCCCTTTC-3' \\
Cyplp011For & 5'-GAACTTCGAGGAAGATAATAGTGTATGGA-3' \\
Cyplp011Rev & 5'-GGAACATTGATACGGAGAGATTAATTAA-3' \\
Cyplp013For & 5'-TCTGAATGGAGGCCTTTGGT-3' \\
Cyplp013Rev & 5'-GGGTTGCAATGTTTATCCGAAT-3' \\
Cyplp015For & 5'-TGACAAGATTCCATCACAGAAGACA-3' \\
Cyplp015Rev & 5'-TTGCCGGGAAGTTTCTCCTT-3' \\
Cyplp023For & 5'-CTAACCTGTCTCACGACGGTCTAA-3' \\
Cyplp023Rev & 5'-TGGATTGTTCACCCACCAATAG-3' \\
Cyplp024For & 5'-TGAGCACTGCAAAGCTTATAAAACTAA-3' \\
Cyplp024Rev & 5'-CTGGTGTCGTAGGCAACTTGAA-3' \\
Cyplp031For & 5'-GCAGCAATTGGCACACGAT-3' \\
Cyplp031Rev & 5'-CCTCAGCAAGTTTATTGCACACTCT-3' \\
\hline
\end{tabular}

$1 \mathrm{~min}$, and a melting step in which the temperature was increased linearly from 55 to $95^{\circ} \mathrm{C}$. Each PCR reaction was done in triplicate and a control sample without template was included. All the data were normalized using Elongation factor $1 \alpha$ as a housekeeping gene (Nicot et al. 2005). When the raw data of the real-time RT-PCR were examined, this sequence showed stable transcript levels throughout the experiment in both the studied genotypes (standard deviation below one PCR cycle for both clones within the experimental period) and therefore, was utilized as a housekeeping gene against which the transcript levels of other profiled genes were normalized. The clonal transcript levels at the start of the experiment were defined as an anchor point against which the transcript levels of all the time points were related by using the formula of Pfaffl (2001):

ratio $=\frac{\left(E_{\text {target }}\right)^{\Delta \mathrm{CP}_{\text {target }}(\text { control-sample })}}{\left(E_{\text {ref }}\right)^{\Delta \mathrm{CP} \text { ref (control-sample })}}$

where "target" is the candidate gene, "ref" the reference gene, "E" the amplification efficiency now assumed to be 2 for all transcripts, and " $\triangle \mathrm{CP}$ " the difference in the critical point value of a transcript (the cycle number at which the fluorescence exceeds that of the background) between the control and the sample.

In our laboratory, 156 cypress sequences had been previously cloned from a subtractive library enriched in genes regulated by low temperature, and deposited in
GenBank (La Porta et al. unpublished). From these sequences, nine were selected now for transcript profiling based on their putative function deduced after a GenBank search for sequence similarity with the BLASTX algorithm (Table 2). The nine sequences were selected in order to cover different aspects of plant response to low temperature, with the aim to find molecular pathways showing significant differences in the two cypress accessions with contrasting freezing tolerance. Regarding the putative role of the profiled genes, cyplp001 was highly homologous to a HSP, cyplp004 a putative chaperonin, cyplp005 showed homology to a chlorophyll-binding protein, cyplp011 to a serine/threonine protein kinase, and cyplp013 to a putative exonuclease. The sequence cyplp015 was chosen to represent dehydrins, a widely studied cold-regulated protein family, while the sequences cyplp023, cyplp024, and cyplp031 represented different members of senescenceassociated protein class.

\section{Results}

$\mathrm{F}_{\mathrm{v}} / \mathrm{F}_{\mathrm{m}}$ measure and electrolyte leakage

A total of 20 cypress accessions were selected for the physiological study. All these accessions had shown good field performance for three consecutive winters from 2004 to 2006 (data not shown). The branches used were all collected in late November, therefore, the plants were considered fully hardened. In order to estimate the lowtemperature damage, both the photosynthetic efficiency $\left(\mathrm{F}_{\mathrm{v}} /\right.$ $F_{m}$ ) and the electrolyte leakage were taken into consideration. When the photosynthetic efficiency was measured $24 \mathrm{~h}$ after freezing at $-15^{\circ} \mathrm{C}$, considerable clonal differences were observed (Fig. 1a). While 14 out of the 20 accessions still showed a high photosynthetic efficiency ( $90 \%$ of the control level or more), six appeared more damaged, having a photosynthetic efficiency ranging from $75.4 \%$ to $89.1 \%$ in relation to the control. Accession 52 seemed to be the most susceptible one, showing a loss of photosynthetic efficiency that was almost 5\% higher than that of the second most damaged accession (accession 67). Accessions 67, 23, and 41 all showed an evident loss of photosynthetic efficiency after exposure to freezing temperature, but the effect was less pronounced, their photosynthetic efficiency ranging from $80.4 \%$ to $83.3 \%$ in relation to the control (Fig. 1a). Among the accessions still showing high photosynthetic efficiency were clones 42 and 30 , which showed a photosynthetic efficiency of $97.5 \%$ and $97.2 \%$, respectively, in relation to the control.

Regarding electrolyte leakage test, the differences among accessions were more pronounced (Fig. 1b). The accession showing the highest ion leakage and thereby the highest 
Table 2 Cypress sequences selected for gene expression analysis. GenBank accession number and putative function based on best homology are shown

\begin{tabular}{|c|c|c|c|}
\hline Sequence name & Accession number & Homology to known genes & E-value \\
\hline cyplp001 & ACA30281.1 & Heat shock protein 17.0, Picea glauca (AAB01561.1) & $5 e-45$ \\
\hline cyplp004 & ACA30284.1 & Chaperonin containing t-complex protein 1, putative, Ricinus communis (EEF36925.1) & $2 \mathrm{e}-50$ \\
\hline cyplp005 & ACA30285.1 & Putative chlorophyll A-B binding protein type I, Pinus pinaster (CAC84495.1) & $3 e-59$ \\
\hline cyplp011 & ACA30291.1 & Serine/threonine protein kinase, putative Ricinus communis (EEF43192.1) & $9 \mathrm{e}-20$ \\
\hline cyplp013 & ACA30292.1 & Exonuclease family protein, Arabidopsis thaliana (NP_196388.1) & $1 \mathrm{e}-15$ \\
\hline cyplp015 & ACA30294.1 & Dehydrin, Prunus persica (AAC49657.1) & $3 e-07$ \\
\hline cyplp023 & ACA30301.1 & Putative senescence-associated protein, Lilium longiflorum (ABO20851.1) & $4 e-42$ \\
\hline cyplp024 & EU430726.1 & Senescence-associated protein, Elaeis guineensis (ACF06508.1) & $1 \mathrm{e}-20$ \\
\hline cyplp031 & ACA30295.1 & Senescence-associated protein DH, Zea mays (ACG43662.1) & $5 e-47$ \\
\hline
\end{tabular}

Fig. 1 a Photosynthetic efficiency $\left(\mathrm{F}_{\mathrm{v}} / \mathrm{F}_{\mathrm{m}}\right)$ of cypress leaves after being incubated at $-15^{\circ} \mathrm{C}$. Data are given in percentage in relation to the photosynthetic efficiency measured in untreated controls. Numbers on $x$-axis indicate the twenty cypress accessions screened. Each data point represents the average of triplicate samples and vertical bars show standard deviations. b Electrolyte leakage of cypress leaf tissue, expressed as a percentage of total electrolytes in the leaves after being incubated at $-15^{\circ} \mathrm{C}$. c Inverse correlation between $\mathrm{Fv} / \mathrm{Fm}$ and electrolyte leakage data obtained on same sample set of twenty cypress clones. $\mathrm{R}^{2}$ is significant at $p<0.01$
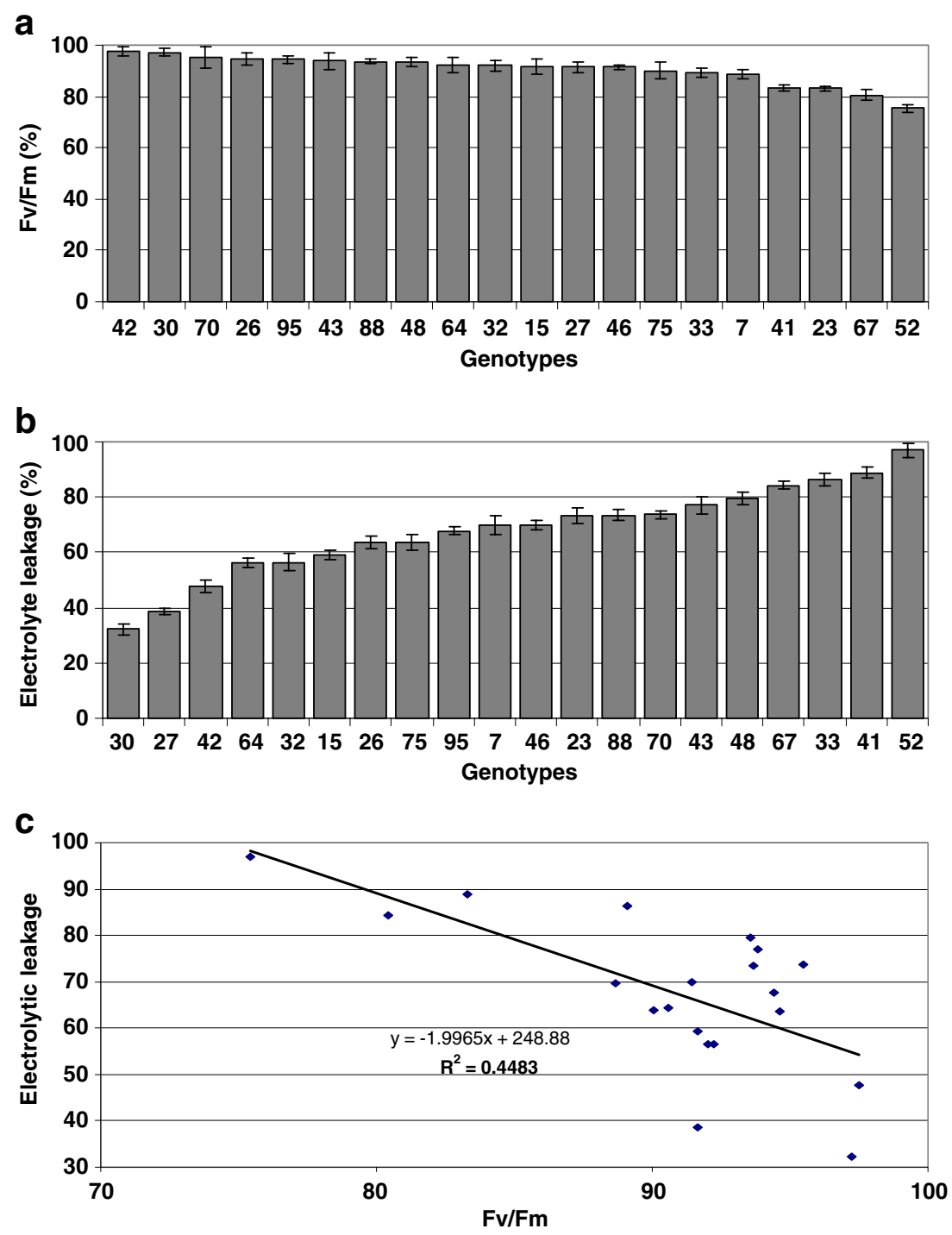
estimated membrane damage was accession $52(97.1 \%$ of the control value), followed by accessions $41(88.9 \%), 33$ (86.4\%), and $67(84.3 \%)$. Accession 30 showed the lowest ion leakage $(32.3 \%$ of the control value), followed by accession 27 (38.7\%). Other clones with good performance included accessions 42 (47.6\%), 64 (56.4\%), and 32 $(56.5 \%)$. When the ranking of clones in the two physiological tests were compared, only partial correlation was found (Fig. 1c). While some of the accessions ranked similarly, others showed somewhat differential performance in the two tests. Accessions 30 and 42 were among the more resistant accessions according to both tests, while accessions 41,52 , and 67 were in both tests classified as very susceptible. Accession 27, on the contrary, showed little membrane damage when electrolyte leakage was measured but only average performance in photosystem activity. A similar pattern was observed for accessions 64, 32, and 15.

\section{Transcipt profiling}

As a first approach, two cypress genotypes that showed contrasting cold tolerance based on photosynthetic efficien-

a

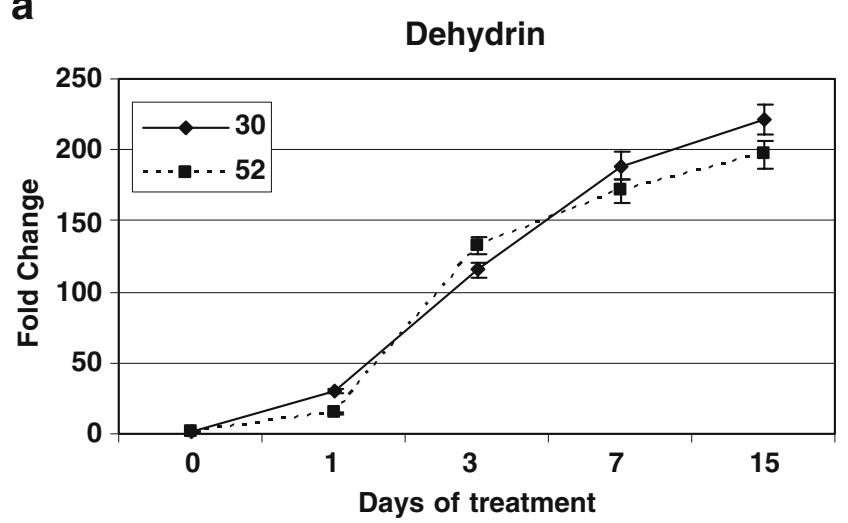

C

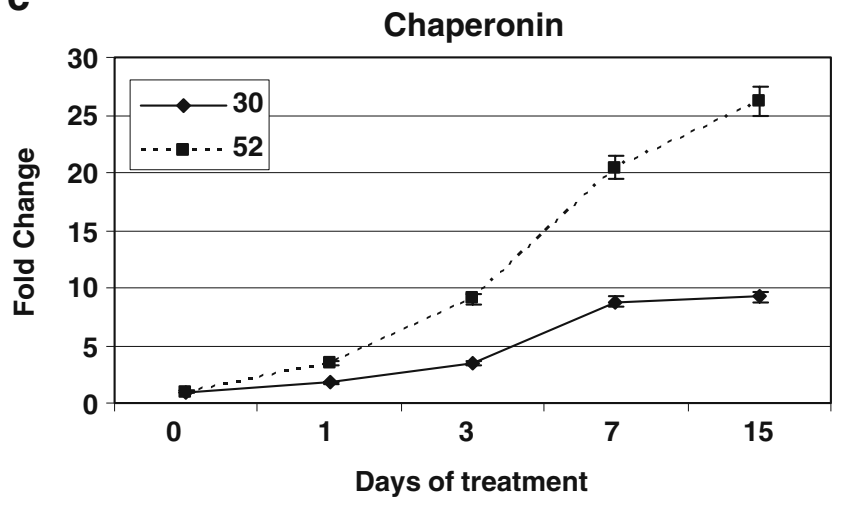

Fig. 2 Transcript profiles of four up-regulated cypress sequences in the cold-tolerant accession 30 and cold-susceptible accession 52 during cold acclimation at $3{ }^{\circ} \mathrm{C}$. a cyplp015, b cyplp011, c cyplp004, d cyplp013. Y-axis shows the relative transcript levels in relation to cy and ion leakage measurements after freezing were subjected to transcript profiling. Accession 52 showed the highest damage in both experiments, while among those accessions showing little damage, accession 30 was selected as the best overall performer. In order to find transcriptional differences during the development of hardening, the transcript levels of the selected sequences were profiled by real-time RT-PCR in these clones for a period of 15 days at $3{ }^{\circ} \mathrm{C}$.

Most of the selected sequences showed similar upregulation patterns between both cypress accessions during the low-temperature treatment, but in some cases, apparent differences could be seen also (Fig. 2). The dehydrin cyplp015 was similarly induced in both accessions during the treatments, transcript levels of the gene showing a continuous increase along with incubation time; after 15 days of incubation at $3^{\circ} \mathrm{C}$, both genotypes showed appr. 200 -fold higher transcript levels than were observed prior to cold exposure (Fig. 2a). Similarly, the serine/threonine kinase cyplp011 showed no differences between the two accessions, its transcript levels peaking 1 day posttreatment, followed by a slight decline after day 3 of cold

b

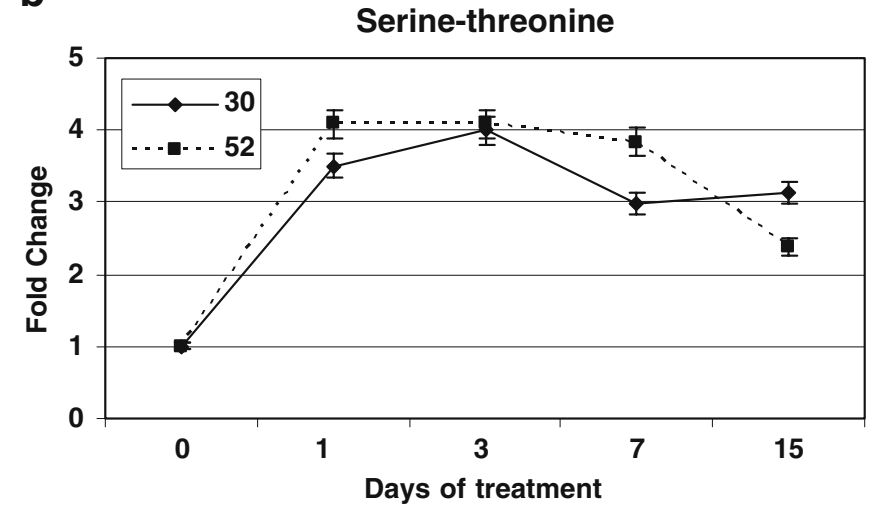

d

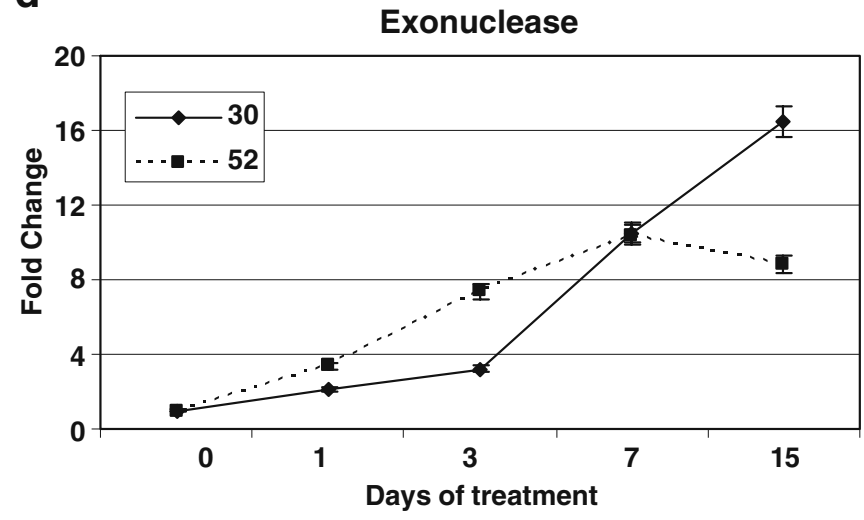

transcript levels measured in control at day 0 and referred to with transcript level value 1 . The standard deviation shown indicates variation between three PCR replicates. All the data were normalized using elongation factor $1 \alpha$ as a housekeeping gene 
treatment (Fig. 2b). In contrast, marked clonal differences were observed in the transcript level of the putative chaperonin cyplp004. A higher induction rate was observed in accession 52 than in accession 30, the clones showing respectively 25 -fold and ninefold higher transcript levels at day 15 post cold exposure, in relation to the start of the experiment (Fig. 2c). The exonuclease cyplp013 showed a higher initial induction rate in clone 52 than in clone 30 , but after day 3, an opposite pattern in induction was true (Fig. 2d).

Not all the sequences studied were up-regulated during cold treatment. Cyplp001 and cyplp005, a HSP and a chlorophyll-binding protein respectively, were both downregulated during exposure to low temperature. For both genes, clone 30 showed higher initial down-regulation rate than clone 52 (Fig. 3a and Fig. 3b). When the three members of the senescence-associated protein family were examined, both clonal and gene-specific regulation patterns were observed. Both clones showed a similar induction rate of cyplp024 up to day 7 post-treatment, after which its transcript level stabilized (Fig. 4a). Regarding cyplp031, its transcript levels stabilized at day 7 in clone 30, whereas clone 52 showed continuously increasing transcript levels throughout the 15-day-long cold exposure (Fig. 4b). The third gene in this group, cyplp023, showed a higher initial induction rate in clone 30 than in clone 52 by day 1 posttreatment, after which the transcript level stabilized in both clones (Fig. 4c).

\section{Discussion}

Plant adaptation to low temperature has been extensively studied, as most of the perennial plants have to cope with winter temperatures below the freezing point and in many cases with temperatures below $-20^{\circ} \mathrm{C}$ (Larcher 2001).

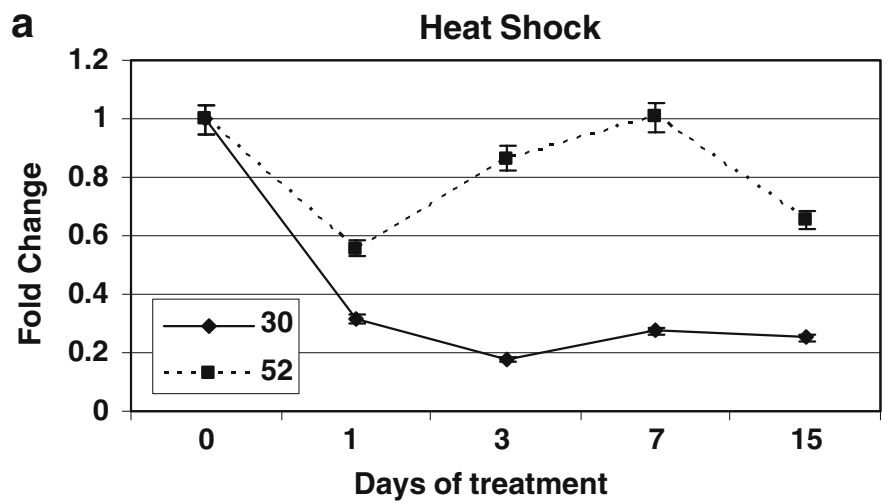

Fig. 3 Transcript profiles of two down-regulated cypress sequences in the cold-tolerant accession 30 and cold-susceptible accession 52 during cold acclimation at $3{ }^{\circ} \mathrm{C}$. a cyplp001, b cyplp005. Y-axis shows the relative transcript levels in relation to transcript levels measured in
Considering the likely climate change-driven anthropogenic northward spread of many plant species that are not always adapted to withstand cold winters (Hansen et al. 2006; Kelly and Goulden 2008), increased knowledge about the molecular mechanisms controlling plant response to low temperature is warranted. This is true especially for those plants, like cypress, that are normally used as ornamental trees and therefore can be planted considerable distances from their natural environment.

Moreover, woody perennial plants are characterized by a long life cycle and are therefore much less suitable than herbaceous species for molecular studies (Wisniewski et al. 2003). Nevertheless, finding new accessions that can survive low temperatures would be of great interest, especially in those areas where a single harsh winter could cause extensive damage.

Plant response to this abiotic stress is extremely complex and involves many different traits of cell biology (Fowler and Thomashow 2002; Hirayama and Shinozaki 2010). An earlier study showed that cypress is capable of responding to low temperature regulating a number of genes that were found involved in hardening development in many species (Pedron et al. 2009), suggesting the presence of coldadaptation mechanisms in this Mediterranean tree.

In order to understand if and how it is possible to exploit differences in low-temperature response among cypress accessions to evaluate different levels of cold tolerance, in the present work, an approach combining physiological and molecular measures was used. To evaluate photosystem II (PSII) damage, chlorophyll fluorescence was measured after freezing of leaf samples to $-15^{\circ} \mathrm{C}$ (Baker 2008). Most of the cypress accessions examined showed little variation in $F_{v} / F_{m}$ when compared to the untreated control (Fig. 1a). This is probably due to the fact that all the samples had been collected in late November when night temperatures in the field ranged between $-1.5^{\circ} \mathrm{C}$ and $-6^{\circ} \mathrm{C}$ (data not

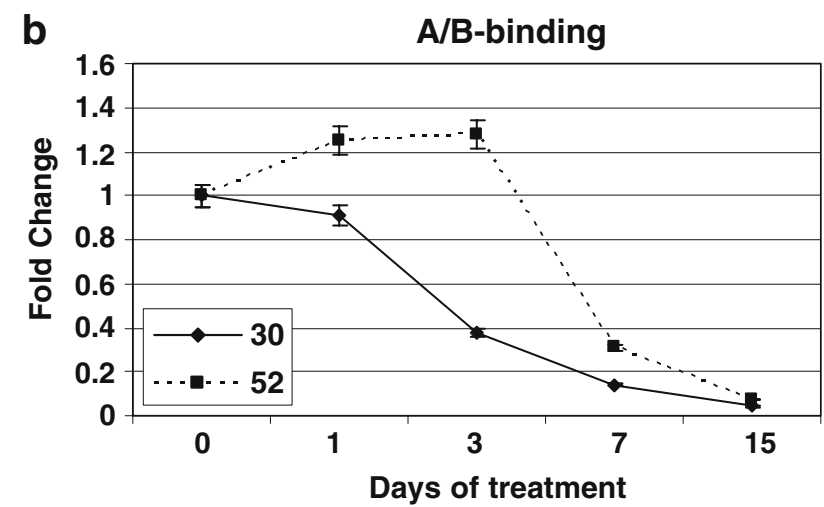

control at day 0 and referred to with transcript level value 1 . The standard deviation shown indicates variation between three PCR replicates. All the data were normalized using elongation factor $1 \alpha$ as a housekeeping gene 
a

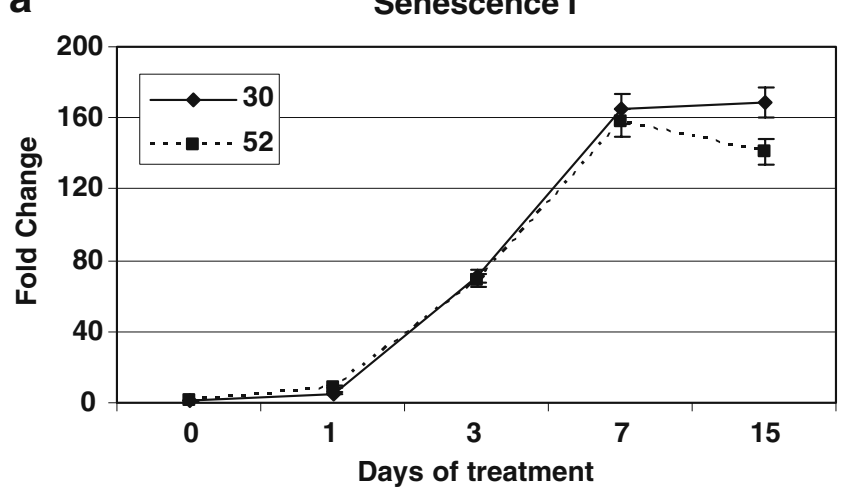

b

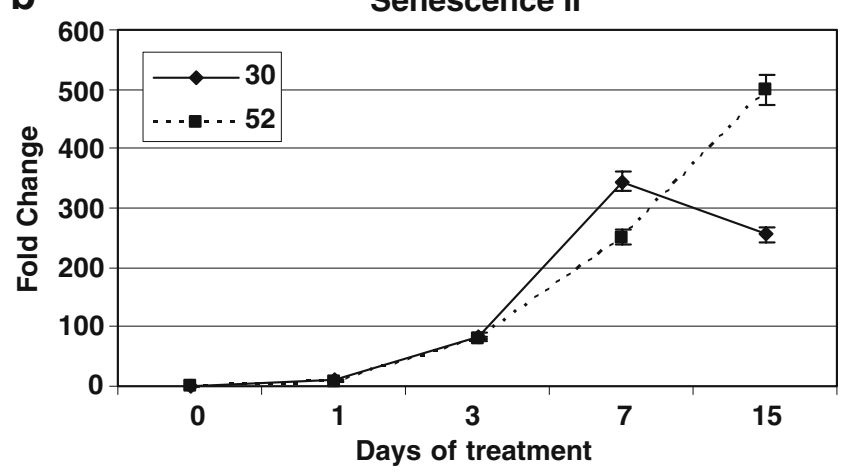

C

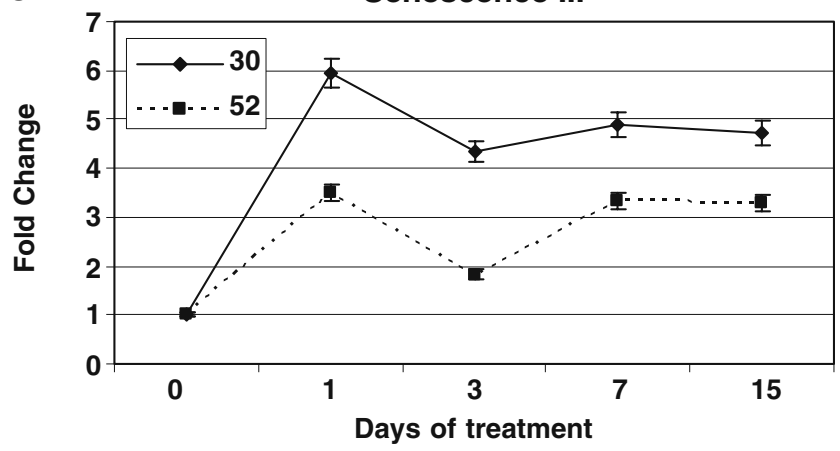

Fig. 4 Transcript profiles of three cypress senescence-associated sequences in the cold-tolerant accession 30 and cold-susceptible accession 52, during cold acclimation at $3^{\circ} \mathrm{C}$. a cyplp024, b cyplp031, c cyplp023. Y-axis shows the relative transcript levels in relation to transcript levels measured in control at day 0 and referred to with transcript level value 1 . The standard deviation shown indicates variation between three PCR replicates. All the data were normalized using elongation factor $1 \alpha$ as a housekeeping gene

shown) and thus, the plants were already fully hardened. It has been shown for many species that freezing tolerance varies between seasons (Corcuera et al. 2005; CavenderBares 2007; Holliday et al. 2008). For example, a clear decrease of $\mathrm{F}_{\mathrm{v}} / \mathrm{F}_{\mathrm{m}}$ value corresponding to tissue damage was observed when needles of contorta pine (Pinus contorta) and Scots pine (Pinus sylvestris) collected from non-acclimated plants at the beginning of September were subjected to freezing stress (Lindgren and Hällgren 1993), whereas no severe inhibition, but only a delay in photosynthetic recovery, was observed when photosynthetic responses of winter-acclimated Scots pine seedlings were followed after transfer to simulated spring conditions with intermittent frost events (Ensminger et al. 2008). Similarly, no considerable changes in $\mathrm{F}_{\mathrm{v}} / \mathrm{F}_{\mathrm{m}}$ were found when leaves from acclimated plants of two evergreen oak species were subjected to $-10^{\circ} \mathrm{C}$ (Cavender-Bares 2007). All these findings from other species are consistent with the results presented in this work and support the application of $\mathrm{F}_{\mathrm{v}} / \mathrm{F}_{\mathrm{m}}$ measurements to identify differences in cypress freezing tolerance. As a conclusion, the accessions showing notably reduced photosynthetic efficiency, and particularly clone 52 which showed only $75.45 \%$ of the control $\mathrm{F}_{\mathrm{v}} / \mathrm{F}_{\mathrm{m}}$, can be considered more susceptible to freezing damage to PSII after hardening development.

Measurement of electrolyte leakage was employed to quantify cold damage to cellular membranes (Hong et al. 2009; Strimbeck et al. 2008). Broad variation was observed among the cypress plants studied (Fig. 1b), accessions 52 and 30 representing the most or least damaged clone, respectively. Correlation between electrolyte leakage and resistance to various abiotic stresses has been established in many plant species. Based on temperature-relative electrolyte leakage curves, Strimbeck et al. 2008 showed that boreal species in the coniferous genera Abies, Picea, and Pinus were capable of more rapid and efficient cold acclimation than the corresponding temperate ones. Interspecific hybrids between Pinus strobus and Pinus wallichiana presented differences in freezing-induced electrolyte leakage in different acclimation stages ( $\mathrm{Lu}$ et al. 2007). All the hybrids containing 75 or $85.7 \%$ Pinus strobus genome showed greater cold hardiness than those containing only $50 \%$ Pinus strobus genome. The electrolyte leakage tests have also been employed to profile differences in cold resistance between different provenances of several oak species (Morin et al. 2007). The electrolyte leakage and photosystem efficiency data were now compared for the cypress clones (Fig. 1c). The moderate correlation obtained between clonal electrolytic leakage and photosystem efficiency following artificial freezing was not surprising, as the two methods take into account different parameters and while electrolyte leakage can be considered an estimate of the cellular membrane damage, $F_{v} / F_{m}$ shows the efficiency of photosystem II, which can be impaired even without physical membrane damage (Saibo et al. 2009; Yamamoto et al. 2008). The two techniques were used to measure cold damage at different freezing temperatures in Arabidopsis (Ehlert and Hincha 2008) and while a general correspondence was found, differences between the two methods were highlighted. According to the results presented in this paper, most of rank changing was observed for those accessions showing average cold tolerance. Again, this was not 
surprising as, especially when $\mathrm{F}_{\mathrm{v}} / \mathrm{F}_{\mathrm{m}}$ was measured, most of the cypress accessions showed very little differences. In order to select two accessions with contrasting frost tolerance to be used in molecular experiments, accession 30 and accession 52 were chosen as contrasts for both chlorophyll fluorescence and electrolyte leakage following freezing.

Most of the candidate transcripts examined were upregulated during cold treatment in both cypress clones displaying difference in cold tolerance (Fig. 2). Recent global monitoring of the Sitka spruce (Picea sitchensis) transcriptome showed considerable reprogramming during autumn cold acclimation; among those up-regulated were dehydrins, pathogenesis-related/antifreeze genes, carbohydrate and lipid metabolism genes, and genes involved in signal transduction and transcriptional regulation (Holliday et al. 2008). Dehydrins are among the most intensively studied cold-inducible genes and are thought to play a protective role during cellular dehydration (Rorat 2006). Over-expression of dehydrins in transformed plants has enhanced freezing tolerance (Peng et al. 2008; Puhakainen et al. 2004). Since their discovery, numerous reports have shown their accumulation in both herbaceous (Welin et al. 1995) and woody species upon cold stress (KontunenSoppela and Laine 2001; Dhanaraj et al 2005). It has been suggested that dehydrins play a role also in winter dormancy, as some members of the family were gradually down-regulated in Norway spruce plants approaching flushing (Yakovlev et al. 2008). For the dehydrin cyplp015, no difference in the up-regulation rate was detected between the two accessions, suggesting that the clonal difference in cold tolerance is not related to transcriptional regulation of these genes. However, it should be kept in mind that the size of these gene families in cypress remains unknown, and that the different members are not necessarily functionally redundant. A search for nucleotide diversity patterns in dehydrins between northern and southern populations of Scots pine showed significant differentiation between populations in allele frequency and haplotype structure of two dehydrins (Wachowiak et al. 2009). Cloning of the different members of the gene family in cypress and investigation of their transcriptional activation and regulatory factors are clearly warranted in future studies on cold tolerance of the species. Serine/threonine protein kinases, particularly a specific class named mitogen-activated protein kinases, are thought to play a central role during the transduction of various cellular signals (Mishra et al. 2006). Another class of kinases containing a serine/threonine domain is the calcineurin Blike protein-interacting protein kinases which have been involved in stress signaling (Xiang et al. 2007). For the serine/threonine cyplp011, no difference in the upregulation rate was now detected between the two accessions. In contrast, apparent clonal differences were detected in the transcript profile of the exonuclease cyplp013, the gene showing a higher initial induction rate in clone 52 than in clone 30. Plant ribonucleases are involved in mRNA degradation during the post-trascriptional control of gene expression (Wilusz and Wilusz 2004). In Arabidopsis a poly(A)-specific ribonuclease (AtPARN) has been related to stress, the gene being induced by high salinity, osmotic stress, and Abscisic acid treatment (Nishimura et al. 2005). The cypress chaperonin (cyplp004) was up-regulated in both clones throughout the experiment, but the coldsusceptible clone 52 showed a higher induction rate. Molecular chaperones represent a protein class responsible for protein folding, assembly, translocation, and degradation, both during normal growing conditions and upon abiotic stress. A function in stabilizing cellular membranes and in protein refolding during stress has been hypothesized for the class (Wang et al. 2004) even if different members are not necessarily functionally redundant, but can differ in cellular localization and function. Obviously, the chaperon gene family provides another promising candidate for cloning and subsequent investigation of the transcriptional activation and regulatory factors of the individual gene family members in cypress. HSPs are also considered to act as molecular chaperones (Iba 2002; Wang et al. 2004). Cyplp001 showed homology to HSP17 class and resulted to be down-regulated especially in accession 30 , while less clear results were found for accession 52 (Fig. 3a). Generally, HSPs are up-regulated in plants during hightemperature treatment (Sapitnitskaya et al. 2006), while their behavior during other abiotic stresses is far less characterized. In apple, different members of the HSP family resulted to be induced after drought treatment, but no over-expression was found following low-temperature treatment (Wisniewski et al. 2008). Several proteins belonging to the HSP family were found differentially expressed in the population of Norway spruce adapted to different elevations (Valcu et al. 2008).

Down-regulation of photosynthetic capacity has been shown to parallel gene regulation in several conifer species: members of the early light-inducible protein family were found to be up-regulated, while photosystem II core protein D1 was down-regulated in winter when photosyntetic efficiency was lower (Zarter et al 2006). The putative chlorophyll a/b-binding protein cyplp005 was downregulated following cold exposure, a higher downregulation rate being observed in the cold-tolerant clone 30 than in the cold-susceptible clone 52. The chlorophyll a/ $b$-binding (Cab) family is composed of at least 30 different members in Arabidopsis (Jansson 1999). These proteins are associated either with photosystem I or photosystem II, and their primary function is to absorb light and to transfer energy to photochemical reaction centers (Green and Durnford 1996). In Arabidopsis, a Cab protein of photo- 
system II was down-regulated during photo-oxidative stress caused by light and cold (Montané et al. 1997), and more recently, a down-regulation of different members of $\mathrm{Cab}$ protein family was demonstrated in apple during lowtemperature exposure (Wisniewski et al. 2008). Finally, the three senescence-associated proteins considered were all up-regulated in both clones following cold exposure, but clone and gene-specific patterns were observed in the transcript profiles. Considering the complexity of senescence regulation, including mobilization and degradation of macromolecules and transient regulation of numerous metabolic pathways (Van Doorn and Woltering 2008; Bailly et al. 2008), it would not be surprising if some of the genes up-regulated during this process also had a role in cold acclimation. An interaction between cold acclimation and metabolic regulation of leaf senescence has been suggested in Arabidopsis (Masclaux-Daubresse et al. 2007).

In conclusion, based on measurement of chlorophyll fluorescence and electrolyte leakage following an artificial freezing test, our data show that cypress accessions display variation in cold tolerance. Two cypress clones, representing extremes in freezing tolerance among the 20 cypress accessions screened, were subjected to transcript profiling of candidate genes upon an experiment where the plants were exposed to $3^{\circ} \mathrm{C}$ for a 15 -day-long incubation period. No clear correlation was found between the physiological and transcript data. In general, it could be envisaged that a rapid host response upon a stress situation is essential for stress tolerance and indeed, the clones displayed differences in the regulation rate of several sequences. Increased knowledge about the roles of such genes during plant low-temperature adaptation is required in order to identify biomarkers that could be used in breeding programs to increase cold tolerance in cypress.

Acknowledgements The authors wish to thank Dr. Paolo Raddi, Mr. Vincenzo Di Lonardo, and Dr. Roberto Danti (IPP-CNR, Florence, Italy) who kindly supplied the selected cypress genotypes used in the experiments. Thanks also to Mr. Emanuel Endrizzi and Dr Giovanna Flaim (FEM-IASMA Research Centre, San Michele all'Adige, Italy) respectively for the technical assistance in the laboratory and for the useful English corrections and suggestion. Finally, the authors wish to also thank Associate Editor Dr Sally N. Aitken and the anonymous reviewers of this manuscript for their valuable comments which have helped us to improve the completeness and overall quality of the paper. This work is part of the project ECOCYPRE (Ecological assessment and sustainable managements of cypress in the landscape of Trentino). It was funded by the Provincia autonoma di Trento through Grant no. 437.

Open Access This article is distributed under the terms of the Creative Commons Attribution Noncommercial License which permits any noncommercial use, distribution, and reproduction in any medium, provided the original author(s) and source are credited.

\section{References}

Bagnoli F, Vendramin GG, Buonamici A, Doulis A, La Porta N, Magri D, Sebastiani F, Raddi P, Fineschi S (2009) Is Cupressus sempervirens native in Italy? An answer from genetic and palaeobotanical data. Mol Ecol 18:2276-2286

Bailly C, El-Maarouf-Bouteau H, Corbineau F (2008) From intracellular signaling networks to cell death: the dual role of reactive oxygen species in seed physiology. C R Biol 331:806-814

Baker NR (2008) Chlorophyll fluorescence: a probe of photosynthesis in vivo. Annu Rev Plant Biol 59:89-113

Baker NR, Rosenqvist E (2004) Applications of chlorophyll fluorescence can improve crop production strategies: an examination of future possibilities. J Exp Bot 55:1607-1621

Binder WD, Fielder P (1996) Chlorophyll fluorescence as in indicator of frost hardiness in white spruce seedlings from different latitudes. New For 11:233-253

Boorse GC, Bosma TL, Meyer AC, Ewers FW, Davis SD (1998) Comparative methods of estimating freezing temperatures and freezing injury in leaves of chaparral shrubs. Int $\mathrm{J}$ Plant Sci 159:513-521

Cavender-Bares J (2007) Chilling and freezing stress in live oaks (Quercus section Virentes): intra- and inter-specific variation in PS II sensitivity corresponds to latitude of origin. Photosynth Res 94:437-453

Chinusamy V, Zhu J, Zhu JK (2007) Cold stress regulation of gene expression in plants. Trends Plant Sci 10:444-451

Cook D, Fowler S, Fiehn O, Thomashow MF (2004) A prominent role for the CBF cold response pathway in configuring the lowtemperature metabolome of Arabidopsis. Proc Natl Acad Sci USA 101:15243-15248

Corcuera L, Morales F, Abadia A, Gil-Pelegrin E (2005) Seasonal changes in photosynthesis and photoprotection in a Quercus ilex subsp ballota woodland located in its upper altitudinal extreme in the Iberian Peninsula. Tree Physiol 25:599-608

Dhanaraj AL, Slovin JP, Rowland LJ (2005) Isolation of a cDNA clone and characterization of expression of the highly abundant, cold acclimation-associated $14 \mathrm{kDa}$ dehydrin of blueberry. Plant Sci 168:949-957

Diaz C, Purdy S, Christ A, Morot-Gaudry J-F, Wingler A, MasclauxDaubresse C (2005) Characterization of new markers to determine the extent and variability of leaf senescence in Arabidopsis thaliana: a metabolic profiling approach. Plant Physiol 138:898-908

Ehlert B, Hincha DK (2008) Chlorophyll fluorescence imaging accurately quantifies freezing damage and cold acclimation responses in Arabidopsis leaves. Plant Methods 4:12

Ensminger I, Schmidt L, Lloyd J (2008) Soil temperature and intermittent frost modulate the rate of recovery of photosynthesis in Scots pine under simulated spring conditions. New Phytol 177:428-442

Fowler S, Thomashow MF (2002) Arabidopsis transcriptome profiling indicates that multiple regulatory pathways are activated during cold acclimation in addition to the CBF cold response pathway. Plant Cell 14:1675-1690

Green BR, Durnford DG (1996) The chlorophyll-carotenoid proteins of oxygenic photosynthesis. Annu Rev Plant Physiol Plant Mol Biol 47:685-714

Hannah MA, Heyer AG, Hincha DK (2005) A global survey of gene regulation during cold acclimation in Arabidopsis thaliana. PLoS Genet 1(2):e26

Hansen J, Sato M, Ruedy R, Lo K, Lea DW, Elizade MM (2006) Global temperature change. Proc Natl Acad Sci USA 103:14288-14293

Hincha DK, Schmitt JM (1992) Freeze-thaw injury and cryoprotection of thylakoid membranes. In: Somero GN, Osmond CB, Bolis CL (eds) Water and Life. Springer, Berlin, pp 316-337 
Hirayama T, Shinozaki K (2010) Research on plant abiotic stress responses in the post-genome era: past, present and future. Plant J 61:1041-1052

Holliday JA, Ralph SG, White R, Bohlmann J, Aitken SN (2008) Global monitoring of autumn gene expression within and among phenotypically divergent populations of Sitka spruce (Picea sitchensis). New Phytol 178:103-122

Hong B, Ma C, Yang Y, Wang T, Yamaguchi-Shinozaki K, Gao J (2009) Over-expression of AtDREB1A in Chrysanthemum enhances tolerance to heat stress. Plant Mol Biol 70:231240

Iba K (2002) Acclimative response to temperature stress in higher plants: approaches of genetic engeneering for temperature tolerance. Annu Rev Plant Biol 53:225-245

IPCC (Intergovernmental Panel on Climate Change) (2007) IPCC fourth assessment report in summary for policymakers IPCC, Geneva. Available via http://www.ipcc.ch/pdf/assessment-report/ ar4/wg1/ar4-wg1-spm.pdf. Accessed 4 Jul 2009

Jansson S (1999) A guide to the Lhc genes and their relatives in Arabidopsis. Trends Plant Sci 4:236-240

Kelly AE, Goulden ML (2008) Rapid shifts in plant distribution with recent climate change. Proc Natl Acad Sci USA 105:1182311826

Kontunen-Soppela S, Laine K (2001) Seasonal fluctuations of dehydrins is related to osmotic status in Scots pine seedlings. Trees 15:425-430

Krause GH, Grafflage S, Rumich-Bayer S, Somersalo S (1988) Effects of freezing on plant mesophyll cells. Symp Soc Exp Biol 2:311327

La Porta N, Bertamini M, Nedunchezhian N, Muthuchelian K (2004) High irradiance induced changes on photosystem 2 in young and mature needles of cypress (Cupressus sempervirens L.). Photosynthetica 42:263-271

La Porta N, Battisti A, Raddi P (2005) Ecological assessment and sustainable management of cypress under climate change conditions in the Italian Alps. Int For Rev 7:5-82

La Porta N, Bertamini M, Nedunchezhian N, Muthuchelian K (2006) Photosynthetic changes that occur during aging of cypress (Cupressus sempervirens L) needles. Photosynthetica 44:555560

Larcher W (2001) Ökophysiologie der Pflanzen (Stuttgart: Eugen Ulmer) ISBN-13 978-3825280741 p. 302

Larcher W (2003) Physiological plant ecology, 4th edn. Springer, Berlin, p 513. ISBN 9783540435167

Lenoir J, Gégout JC, Marquet PA, de Ruffray P, Brisse H (2008) A significant upward shift in plant species optimum elevation during the 20th century. Science 230:1768-1771

Lindgren K, Hällgren JE (1993) Cold acclimation of Pinus contorta and Pinus sylvestris assessed by chlorophyll fluorescence. Tree Physiol 13:97-106

Lopez-Matas M-A, Nuñez P, Soto A, Allona I, Casado R, Collada C, Guevara MA, Aragoncillo C, Gomez L (2004) Protein cryoprotective activity of a cytosolic small heat shock protein that accumulates constitutively in chestnut stems and is upregulated by low and high temperatures. Plant Physiol 134 (4): 1708-1717

Lu P, Colombo SJ, Sinclair RW (2007) Cold hardiness of interspecific hybrids between Pinus strobus and P. wallichiana measured by post-freezing needle electrolyte leakage. Tree Physiol 27:243250

Masclaux C, Valadier MH, Brugie're N, Morot-Gaudry JF, Hirel B (2000) Characterization of the sink/source transition in tobacco (Nicotiana tabacum $\mathrm{L}$ ) shoots in elation to nitrogen management and leaf senescence. Planta 211:510-518

Masclaux-Daubresse C, Purdy S, Lemaitre T, Pourtau N, Taconnat L, Renou JP, Wingler A (2007) Genetic variation suggests interac- tion between cold acclimation and metabolic regulation of leaf senescence. Plant Physiol 143:434-446

Mishra NS, Tuteja R, Tuteja N (2006) Signalling through MAP kinase networks in plants. Arch Biochem Biophys 425:55-68

Mohammed GH, Binder WD, Gillies SL (1995) Chlorophyll fluorescence - a review of its practical forestry applications and instrumentation. Scand J For Res 10:383-410

Montané MH, Dreyer S, Triantaphylides C, Kloppstech K (1997) Early light-inducible proteins during long-term acclimation of barley to photooxidative stress caused by light and cold: high level of accumulation by posttranscriptional regulation. Planta 202:293-302

Morin X, Améglio T, Ahas R, Kurz-Besson C, Lanta V, Leburgeois F, Miglietta F, Chuine I (2007) Variation in cold hardiness and carbohydrate concentration from dormancy induction to bud burst among provenances of three European oak species. Tree Physiol 27:817-825

Moser C, Gatto P, Moser M, Pindo M, Velasco R (2004) Isolation of functional RNA from grapevine and apple tissues with a modified hot borate method. Mol Biotechnol 26:95-99

Muthuchelian K, Bertamini M, La Porta N, Nedunchezhian N (2005) Photoinhibition and recovery of photosynthesis in cankersusceptible and resistant needles of cypress (Cupressus sempervirens L). J Phytopathol 153:337-343

Nicot N, Hausman JF, Hoffman L, Evers D (2005) Housekeeping gene selection for real-time RT-PCR normalization in potato during biotic and abiotic stress. J Exp Bot 56:2907-2914

Nishimura N, Kitahata N, Seki M, Narusaka Y, Narusaka M, Kuromori T, Asami T, Shinozaki K, Hirayama T (2005) Analysis of ABA Hypersensitive Germination2 revealed the pivotal functions of PARN in stress response in Arabidopsis. Plant $\mathrm{J}$ 44:972-984

Pearce RS (2001) Plant freezing and damage. Ann Bot 87:417-424

Pedron L, Baldi P, Hietala AM La Porta N (2009) Genotype-specific regulation of cold-responsive genes in cypress (Cupressus sempervirens). Gene 437:45-53

Peng Y, Reyes JL, Wei H, Yang Y, Karlson D, Covarrubias AA, Krebs SL, Fessehaie A, Arora R (2008) RcDhn5, a cold acclimationresponsive dehydrin from Rhododendron catawbiense rescues enzyme activity from dehydration effects in vitro and enhances freezing tolerance in RcDhn5-overexpressing Arabidopsis plants. Physiol Plant 134:583-597

Pfaffl MW (2001) A new mathematical model for relative quantification in real-time RT-PCR. Nucleic Acids Res 29:2002-2007

Puhakainen T, Hess MW, Mäkelä P, Svensson J, Heino P, Palva ET (2004) Overexpression of multiple dehydrin genes enhances tolerance to freezing stress in Arabidopsis. Plant Mol Biol $54: 743-753$

Raddi P, Panconesi A (1989) Genetic variability of tolerance to cold in Cupressus sempervirens progenies. Silvae Genet 38:168-172

Renaut J, Hausman JF, Bassett C, Artlip T, Cauchie HM, Witters E, Wisniewski M (2008) Quantitative proteomic analysis of short photoperiod and low-temperature responses in bark tissues of peach (Prunus persica L. Batsch). Tree Genetics \& Genomes 4:589-600

Rohde P, Hincha DK, Heyer AG (2004) Heterosis in the freezing tolerance of crosses between two Arabidopsis thaliana accessions (Columbia-0 and C24) that show differences in nonacclimated and acclimated freezing tolerance. Plant J 38:790-799

Rorat T (2006) Plant dehydrins-tissue location, structure and function. Cell Mol Biol Lett 11:536-556

Saibo NJ, Laurenço T, Oliveira MM (2009) Transcription factors and regulation of photosynthetic and related metabolism under environmental stresses. Ann Bot 103:609-623

Sapitnitskaya M, Maul P, McCollum GT, Guy CL, Weiss B, Samach A, Porat R (2006) Postharvest heat and conditioning treatments 
activate different molecular responses and reduce chilling injuries in grapefruit. J Exp Bot 57:2943-2953

Schmidt JE, Schmitt JM, Kaiser WM, Hincha DK (1986) Salt treatment induces frost hardiness in leaves and isolated thylakoids from spinach. Planta 168:50-55

Smallwood M, Bowles DJ (2002) Plants in a cold climate. Philos Trans R Soc Lond B Biol Sci 357:831-847

Strimbeck GR, Kjellsen TD, Schaberg PG, Murakami PF (2008) Dynamics of low-temperature acclimation in temperate and boreal conifer foliage in a mild winter climate. Tree Physiol 28:1365-1374

Thomashow MF (1999) Plant cold acclimation: freezing tolerance genes and regulatory mechanisms. Annu Rev Plant Physiol Plant Mol Biol 50:571-599

Ukaji N, Kuwabara C, Takezawa D, Arakawa K, Yoshida S, Fujikawa S (1999) Accumulation of small heat-shock protein homologs in the endoplasmic reticulum of cortical parenchyma cells in mulberry in association with seasonal cold acclimation. Plant Physiol 120:481-489

Valcu CM, Lalanne C, Plomion C, Schlink K (2008) Heat induced changes in protein expression profiles of Norway spruce (Picea abies) ecotypes from different elevations. Proteomics 8:42874302

Van Doorn WG, Woltering EJ (2008) Physiology and molecular biology of petal senescence. J Exp Bot 59:453-480

Xiang Y, Huang Y, Xiong L (2007) Characterization of stressresponsive CIPK genes in rice for stress tolerance improvement. Plant Physiol 144:1416-1428

Wachowiak W, Balk PA, Savolainen O (2009) Search for nucleotide diversity patterns of local adaptation in dehydrins and other coldrelated candidate genes in Scots pine (Pinus sylvestris L.). Tree Genetics \& Genomes 5:117-132
Wang WX, Vinocur B, Shoseyov O, Altman A (2004) Role of plant heat-shock proteins and molecular chaperones in the abiotic stress response. Trends Plant Sci 9:244-252

Welin BV, Olson A, Palva ET (1995) Structure and organization of two closely related low-temperature-induced dhn/lea/rab-like genes in Arabidopsis thaliana L Heynh. Plant Mol Biol 29:391-395

Wilusz CJ, Wilusz J (2004) Bringing the role of mRNA decay in the control of gene expression into focus. Trends Genet 20:491-497

Wisniewski ME, Bassett C, Gusta LV (2003) An overview of cold hardiness in woody plants: seeing the forest through the trees. Hort Sci 38:952-959

Wisniewski ME, Bassett C, Norelli J, Macarisin D, Artlip T, Gasic K, Korban S (2008) Expressed sequence tag analysis of the response of apple (Malus x domestica 'Royal Gala') to low temperature and water deficit. Physiol Plant 133:298-317

Yakovlev IA, Asante DKA, Fossdal CG, Partanen J, Junttila O, Johnsen Ø (2008) Dehydrins expression related to timing of bud burst in Norway spruce. Planta 228:459-472

Yamamoto Y, Aminaka R, Yoshioka M, Khatoon M, Komayama K, Takenaka D, Yamashita A, Nijo N, Inagawa K, Morita N, Sasaki T, Yamamoto Y (2008) Quality control of photosystem II: impact of light and heat stress. Photosymyh Res 98:589-608

Zarter CR, Adams WW III, Ebbert W, Cuthbertson DJ, Adamska I, Demming-Adams B (2006) Winter down-regulation of intrinsic photosynthetic capacity coupled with up-regulation of ELIP-like proteins and persistent energy dissipation in a subalpine forest. New Phytol 172:272-282

Zocca A, Zanini C, Aimi A, Frigimelica G, La Porta N, Battisti A (2008) Spread of plant pathogens and associated insect vectors at the northern range margin of cypress in Italy. Acta Oecol 33:307313 